\title{
Beta cell glucose sensitivity is decreased by $39 \%$ in non-diabetic individuals carrying multiple diabetes-risk alleles compared with those with no risk alleles
}

\author{
L. Pascoe • T. M. Frayling • M. N. Weedon • A. Mari • \\ A. Tura $\cdot$ E. Ferrannini $\cdot$ M. Walker • \\ on behalf of the RISC Consortium
}

Received: 30 April 2008 / Accepted: 9 July 2008 / Published online: 22 August 2008

(C) Springer-Verlag 2008

\begin{abstract}
Aims/hypothesis Novel type 2 diabetes-susceptibility loci have been identified with evidence that individually they mediate the increased diabetes risk through altered pancreatic beta cell function. The aim of this study was to test the cumulative effects of diabetes-risk alleles on measures of beta cell function in non-diabetic individuals.

Methods A total of 1,211 non-diabetic individuals underwent metabolic assessment including an OGTT, from which measures of beta cell function were derived. Individuals were genotyped at each of the risk loci and then classified according to the total number of risk alleles that they carried. Initial analysis focused on CDKAL1, HHEX/IDE and TCF7L2 loci, which were individually associated with
\end{abstract}

Electronic supplementary material The online version of this article (doi:10.1007/s00125-008-1124-7) contains a list of the members of the RISC Consortium, which is available to authorised users.

L. Pascoe $\cdot$ M. Walker $(\bowtie)$

School of Clinical Medical Sciences,

4th Floor William Leech Building, The Medical School,

Newcastle University, Framlington Place,

Newcastle upon Tyne NE2 4HH, UK

e-mail: mark.walker@ncl.ac.uk

T. M. Frayling $\cdot$ M. N. Weedon

Peninsula Medical School,

Diabetes Genetics Group and Genetics of Complex Traits,

Exeter, UK

A. Mari $\cdot$ A. Tura

CNR Institute of Biomedical Engineering,

Padova, Italy

E. Ferrannini

School of Medicine, University of Pisa,

Pisa, Italy a decrease in beta cell function in our cohort. Risk alleles for $C D K N 2 A / B, S L C 30 A 8, I G F 2 B P 2$ and $K C N J 11$ loci were subsequently included into the analysis.

Results The diabetes-risk alleles for CDKAL1, HHEX/IDE and TCF7L2 showed an additive model of association with measures of beta cell function. Beta cell glucose sensitivity was decreased by $39 \%$ in those individuals with five or more risk alleles compared with those individuals with no risk alleles (geometric mean [SEM]: 84 [1.07] vs 137 [1.11]

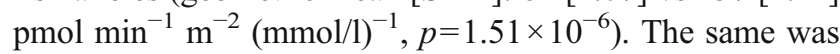
seen for the $30 \mathrm{~min}$ insulin response $\left(p=4.17 \times 10^{-7}\right)$. The relationship remained after adding in the other four susceptibility loci (30 min insulin response and beta cell glucose sensitivity, $p<0.001$ and $p=0.003$, respectively). Conclusions/interpretation This study shows how individual type 2 diabetes-risk alleles combine in an additive manner to impact upon pancreatic beta cell function in nondiabetic individuals.

Keywords Pancreatic beta cell glucose sensitivity .

Susceptibility genes - Thirty minute insulin response .

Type 2 diabetes

\author{
Abbreviations \\ RISC Relationship between Insulin Sensitivity and Car- \\ diovascular Disease study \\ SNP single-nucleotide polymorphism
}

\section{Introduction}

Recent genome-wide association analyses have identified novel type 2 diabetes susceptibility loci. These singlenucleotide polymorphisms (SNPs) have been detected 
within or close to $F T O, C D K N 2 A / B, I G F 2 B P 2, S L C 30 A 8$, $C D K A L 1$ and $H H E X / I D E$, along with confirming the involvement of TCF7L2, PPARG and KCNJ11 [1-6]. Many of the confirmed type 2 diabetes variants have since been shown in population cohorts to alter beta cell function [713]. These studies include the RISC (Relationship between Insulin Sensitivity and Cardiovascular Disease) study [14], where we previously showed that CDKAL1 (rs10946398) and HHEX/IDE (rs1111875) loci were associated with altered beta cell function as measured by the $30 \mathrm{~min}$ insulin response and pancreatic beta cell glucose sensitivity derived from an OGTT [10]. The aim of this study was to test the cumulative effects of variants shown individually to alter beta cell function.

\section{Methods}

We included the CDKAL1 (rs10946398) and the HHEX/IDE (rs1111875) susceptibility loci as we have shown previously that they significantly affect pancreatic beta cell function individually in the RISC cohort. We also included TCF7L2 (rs7903146), as it remains the strongest genetic predictor of type 2 diabetes, and has been reported to associate with decreased pancreatic beta cell function $[8,15]$. We next included these loci and those of the other four genes reported to alter beta cell function, $C D K N 2 A / B$ (rs10811661), IGF2BP2 (rs4402960), SLC30A8 (rs13266634) and KCNJ11 (rs5219), in our model to test the effects of all seven variants. To do this we used the RISC cohort that comprises non-diabetic men and women of European ancestry from 19 centres across 13 different countries [14]. Volunteers were recruited as part of a long-term study of insulin sensitivity and cardiovascular disease and those with diabetes, hypertension or dyslipidaemia were excluded. The analysis presented here is based on 1,211 individuals who had passed the eligibility criteria and had completed genotype data. We studied the same indices of pancreatic beta cell function. The $30 \mathrm{~min}$ insulin response is the ratio of the insulin concentration increment to the $30 \mathrm{~min}$ glucose concentration ([30 $\mathrm{min}$ insulin (pmol/l)-0 $\mathrm{min}$ insulin $(\mathrm{pmol} / \mathrm{l})] /[30 \mathrm{~min}$ glucose $(\mathrm{mmol} / \mathrm{l})])$. Pancreatic beta cell glucose sensitivity is the slope of the doseresponse curve between model-derived measures of insulin secretion vs plasma glucose concentration achieved during the OGTT [16]. $\log _{10}$ transformation was used to normalise distributions and data are reported as geometric mean and SEM. Individuals were genotyped by KBioscience (http://www.kbioscience.co.uk/) at each of the type 2 diabetes-risk loci and then classified according to the total number of risk alleles that they carried. So for the initial three loci analysis, an individual homozygous for the risk allele at one locus, and heterozygous at the other two loci would carry a total of four risk alleles. Individuals with five or six risk alleles were grouped together in view of the relatively small number of individuals. For the analysis which looked at all seven loci, individuals were grouped together if they carried four or fewer, or nine or more. Statistical analyses were performed using Minitab version 15. Linear trend analysis (additive model) was performed to test for associations between the CDKAL1, HHEX/IDE and $T C F 7 L 2$ SNP genotypes and $30 \mathrm{~min}$ insulin response, then beta cell glucose sensitivity after adjusting for age, sex and recruitment centre. Interaction analysis was performed using Stata. $p<0.05$ was considered statistically significant.

\section{Results and discussion}

All SNPs were in Hardy-Weinberg equilibrium. Although all analyses were corrected for recruitment centre, we

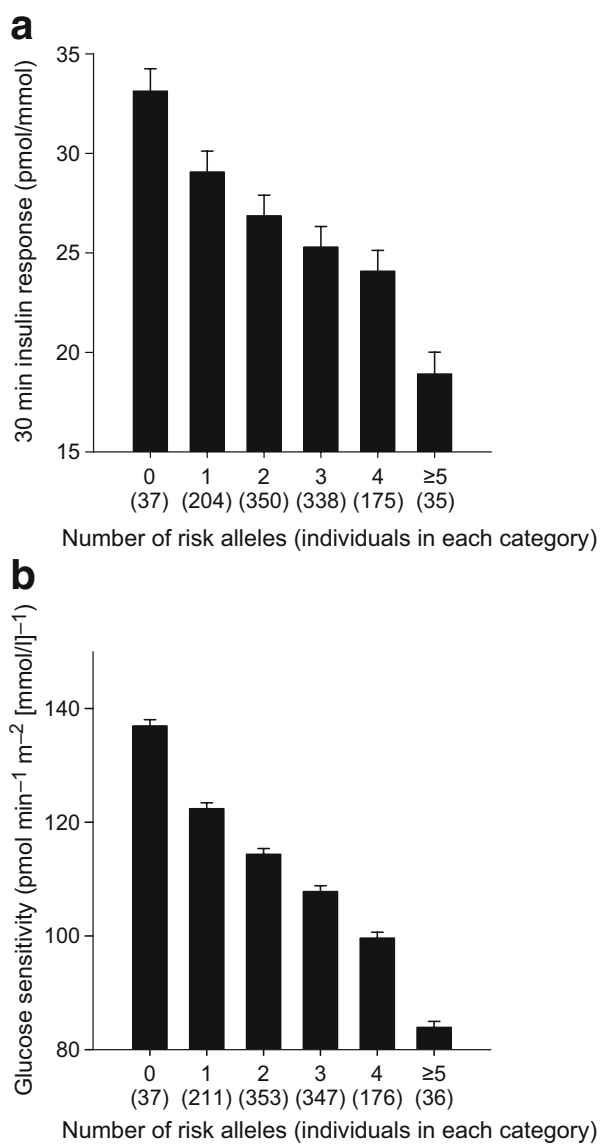

Fig. 1 Relationships between CDKAL1 (rs10946398), HHEX/IDE (rs1111875) and TCF7L2 (rs7903146) combined genotypes and $30 \mathrm{~min}$ insulin response (a), $p=4.17 \times 10^{-7}$, and beta cell glucose sensitivity (b), $p=1.51 \times 10^{-6}$. Blood was sampled at $30 \mathrm{~min}$ intervals during the OGTT to form the basis for modelling the estimates of glucose sensitivity. Data are presented as the geometric mean (SEM) after adjustment for age, sex and recruitment centre 
compared genotype frequencies between individuals from North and South European recruitment centres and found no significant differences.

First, we confirmed that the TCF7L2 risk allele was individually associated with decreased early insulin response to an OGTT $(p=0.038)$ as previously reported [15]. Combining the diabetes-risk alleles for CDKAL1 (rs10946398), HHEX/IDE (rs1111875) and TCF7L2 (rs7903146) loci showed an additive model of association with measures of beta cell function. The additive effects of the three risk variants were associated with a decrease in $30 \mathrm{~min}$ insulin response $\left(p=4.17 \times 10^{-7}\right)$. This was decreased by $43 \%$ in the $3.1 \%$ of the cohort with five or more risk alleles compared with the $3.2 \%$ that carried no risk alleles (geometric mean [SEM]) (18.9 [1.09] vs 33.1 [1.12] pmol/mmol). The same was seen with beta cell glucose sensitivity (Fig. 1, $p=1.51 \times 10^{-6}$ ). This was decreased by $39 \%$ in those individuals with five or more risk alleles compared with those individuals with no risk alleles (84 [1.07] vs 137 [1.11] pmol $\left.\mathrm{min}^{-1} \mathrm{~m}^{-2}[\mathrm{mmol} / \mathrm{l}]^{-1}\right)$. Interaction analyses showed that none of the comparisons was significantly different between a purely additive model and a full model containing interaction terms. From this we can determine that there is no evidence of deviation from additive effects within or between the susceptibility loci. Other key demographic and metabolic data for the individuals with combined risk alleles are summarised in Table 1.

Although the other novel genes, $C D K N 2 A / B, I G F 2 B P 2$, $S L C 30 A 8$ and KCNJ11 have been shown to be associated with indices of pancreatic beta cell function in other studies $[7,11,12]$, they did not reach statistical significance individually in our cohort [10]. However, when we included them in our additive model the relationships between increasing number of risk alleles and decreasing $30 \mathrm{~min}$ insulin response and decreasing beta cell glucose sensitivity still remained significant $(p<0.001$ and $p=0.003$, respectively). Between the $8 \%$ of the cohort with four or fewer risk alleles and the $16.8 \%$ with nine or more risk alleles there was a $21.8 \%$ decrease in $30 \mathrm{~min}$ insulin response and $29.6 \%$ decrease in pancreatic beta cell glucose sensitivity.

We have previously shown that common type 2 diabetes risk alleles combine in an additive manner to increase diabetes risk in individuals carrying multiple susceptibility alleles [17]. This is the first study to show that risk alleles individually associated with impaired pancreatic beta cell function combine in the same additive manner to markedly decrease beta cell function in individuals carrying multiple susceptibility alleles. The additive impact upon beta cell glucose sensitivity is of particular interest, as decreased beta cell glucose sensitivity in non-diabetic individuals has been shown to be a powerful, independent predictor for progression to type 2 diabetes [18]. Importantly, the decrease in the indices of beta cell function with increasing number of risk alleles was not a function of changes in whole-body insulin sensitivity $(M / I)$, which essentially remained unchanged, as shown in Table 1.

Further testing in other population-based studies is required to validate our results. Larger studies have also confirmed susceptibility loci within the SLC $30 A 8$, $C D K N 2 A / B, I G F 2 B P 2$ and $K C N J 11$ genes as altering beta cell function, so larger studies may refine our initial estimates [7, 11, 12].

Table 1 Relationships between CDKAL1, HHEX/IDE and TCF7L2 combined genotypes and key demographic and metabolic measures

\begin{tabular}{|c|c|c|c|c|c|c|}
\hline \multirow[t]{2}{*}{ Variable } & \multicolumn{6}{|c|}{ Number of risk alleles } \\
\hline & 0 & 1 & 2 & 3 & 4 & $5+$ \\
\hline Number of individuals & 39 & 214 & 374 & 363 & 183 & 38 \\
\hline Age (years) & $44(1.34)$ & $44(0.59)$ & $44(0.43)$ & $44(0.44)$ & $43(0.58)$ & $46(1.41)$ \\
\hline BMI $\left(\mathrm{kg} / \mathrm{m}^{2}\right)$ & $26(0.66)$ & $26(0.29)$ & $26(0.20)$ & $25(0.22)$ & $26(0.30)$ & $24(0.49)$ \\
\hline Fasting glucose $(\mathrm{mmol} / \mathrm{l})$ & $5.0(0.07)$ & $5.0(0.04)$ & $5.1(0.03)$ & $5.1(0.05)$ & $5.1(0.05)$ & $5.1(0.10)$ \\
\hline $2 \mathrm{~h}$ glucose $(\mathrm{mmol} / \mathrm{l})$ & $5.5(0.21)$ & $5.6(0.10)$ & $5.8(0.07)$ & $5.7(0.08)$ & $5.9(0.13)$ & $5.7(0.22)$ \\
\hline Fasting insulin $(\mathrm{pmol} / \mathrm{l})$ & $33(22-43)$ & $30(20-46)$ & $31(21-44)$ & $30(21-45)$ & $33(22-44)$ & $27(21-38)$ \\
\hline$\left.M / I(\mathrm{mmol} \mathrm{min}-1 \text { [kg FFM }]^{-1}[\mathrm{nmol} / 1]^{-1}\right)$ & $124(93-170)$ & $136(90-183)$ & $127(92-171)$ & $127(93-180)$ & $121(89-180)$ & $125(93-164)$ \\
\hline Insulinogenic index $(\mathrm{pmol} / \mathrm{mmol})$ & $91(66-153)$ & $89(58-133)$ & $79(50-118)$ & $75(46-109)$ & $69(47-110)$ & $49(32-73)^{\mathrm{a}}$ \\
\hline \multicolumn{7}{|l|}{ Glucose tolerance } \\
\hline NGT $(\%)$ & 100 & 80 & 86 & 89 & 84 & 83 \\
\hline $\mathrm{IFG} \pm \mathrm{IGT}(\%)$ & 0 & 20 & 14 & 11 & 16 & 17 \\
\hline Diabetes family history (\%) & 30 & 23 & 29 & 26 & 31 & 28 \\
\hline
\end{tabular}

Data are means (SEM), except fasting insulin, whole-body insulin sensitivity measured by hyperinsulinaemic clamp $(M / I)$ and insulinogenic index ([30 min insulin (pmol/l)-0 min insulin $(\mathrm{pmol} / \mathrm{l})] /[30 \mathrm{~min}$ glucose $(\mathrm{mmol} / \mathrm{l})-0$ min glucose $(\mathrm{mmol} / \mathrm{l})])$, which are presented as median (interquartile range)

${ }^{\text {a }}$ For linear trend analysis correcting for age, sex and centre, $p<0.0001$

FFM, fat-free mass; IFG, impaired fasting glucose; IGT, impaired glucose tolerance; NGT, normal glucose tolerance 
In conclusion, while individual susceptibility alleles only moderately alter pancreatic beta cell function, the risk is additively increased when risk alleles are combined. Our study provides a validation of the additive model by which risk alleles combine to increase disease susceptibility.

Acknowledgements The RISC Study is supported by European Union grant QLG1-CT-2001-01252 and AstraZeneca. L. Pascoe is the recipient of a joint BBSRC and Unilever UK CASE PhD studentship.

Duality of interest The authors declare that there is no duality of interest associated with this manuscript.

\section{References}

1. Sladek R, Rocheleau G, Rung J et al (2007) A genome-wide association study identifies novel risk loci for type 2 diabetes. Nature 445:881-885

2. Frayling TM, Timpson NJ, Weedon MN et al (2007) A common variant in the FTO gene is associated with body mass index and predisposes to childhood and adult obesity. Science 316:889-894

3. Diabetes Genetics Initiative of Broad Institute of Harvard and MIT Lund University and Novartis Institutes of BioMedical Research (2007) Genome-wide association analysis identifies loci for type 2 diabetes and triglyceride levels. Science 316:1331-1336

4. Zeggini E, Weedon MN, Lindgren CM et al (2007) Replication of genome-wide association signals in UK samples reveals risk loci for type 2 diabetes. Science 316:1336-1341

5. Scott LJ, Mohlke KL, Bonnycastle LL et al (2007) A genomewide association study of type 2 diabetes in Finns detects multiple susceptibility variants. Science 316:1341-1345

6. Steinthorsdottir V, Thorleifsson G, Reynisdottir I et al (2007) A variant in $C D K A L 1$ influences insulin response and risk of type 2 diabetes. Nat Genet 39:770-775

7. Nielsen E-MD, Hansen L, Carstensen B et al (2003) The E23K variant of Kir6.2 associates with impaired post-OGTT serum insulin response and increased risk of type 2 diabetes. Diabetes 52:573-577
8. Loos RJF, Franks PW, Francis RW et al (2007) TCF7L2 polymorphisms modulate proinsulin levels and beta-cell function in a British Europid population. Diabetes 56:1943-1947

9. Staiger H, Machicao F, Stefan N et al (2007) Polymorphisms within novel risk loci for type 2 diabetes determine beta-cell function. PLoS ONE 2:e832

10. Pascoe L, Tura A, Patel S et al (2007) Common variants of the novel type 2 diabetes genes, CDKAL1 and HHEX/IDE, are associated with decreased pancreatic beta-cell function. Diabetes 56:3101-3104

11. Grarup N, Rose CS, Andersson EA et al (2007) Studies of association of variants near the $H H E X, C D K N 2 A / B$, and $I G F 2 B P 2$ genes with type 2 diabetes and impaired insulin release in 10,705 Danish subjects: validation and extension of genome-wide association studies. Diabetes 56:3105-3111

12. Boesgaard T, Žilinskaitė J, Vänttinen M et al (2008) The common SLC30A8 Arg325Trp variant is associated with reduced firstphase insulin release in 846 non-diabetic offspring of type 2 diabetes patients - the EUGENE2 study. Diabetologia 51:816820

13. Stancakova A, Pihlajamaki J, Kuusisto J et al (2008) Single nucleotide polymorphism rs 7754840 of CDKAL1 is associated with impaired insulin secretion in non-diabetic offspring of type 2 diabetic subjects and in a large sample of men with normal glucose tolerance. J Clin Endocrinol Metab 93:1924-1930

14. Hills S, Balkau B, Coppack S et al (2004) The EGIR-RISC STUDY (The European group for the study of insulin resistance: relationship between insulin sensitivity and cardiovascular disease risk): I. Methodology and objectives. Diabetologia 47:566-570

15. Lyssenko V, Lupi R, Marchetti P et al (2007) Mechanisms by which common variants in the TCF $7 L 2$ gene increase risk of type 2 diabetes. J Clin Invest 117:2155-2163

16. Mari A, Tura A, Gastaldelli A, Ferrannini E (2002) Assessing insulin secretion by modelling in multiple-meal tests: role of potentiation. Diabetes 51(Suppl 1):S221-S226

17. Weedon MN, McCarthy MI, Hitman G et al (2006) Combining information from common type 2 diabetes risk polymorphisms improves disease prediction. PLoS Medicine 3:e374

18. Walker M, Mari A, Jayapaul M, Bennett S, Ferrannini E (2006) Impaired beta-cell glucose sensitivity and whole-body insulin sensitivity as predictors of hyperglycaemia in non-diabetic subjects. Diabetologia 49:1456-1456 